\title{
Managing Severe COPD: Addressing the Challenges with Latest Trends and Treatment Options (Part II: Non-Pharmacological Management)
}

\author{
Khajotia $\mathbf{R}^{1^{*}}$, Raman $\mathbf{K}^{2}$ and Khajotia $\mathbf{K}^{3}$ \\ ${ }^{1}$ Hospital Tuanku Ja'afar, International Medical University, Seremban, Malaysia \\ ${ }^{2}$ Hospital Tuanku Ja'afar, Seremban, Malaysia \\ ${ }^{3}$ MIMER Medical College, Talegaon, Dist. Pune, India
}

*Corresponding author: Khajotia R, Hospital Tuanku Ja'afar, International Medical University, Seremban, Malaysia, Tel: (00606) 767 7798, Fax: 06-762 5771; E-mail: rumi@imu.edu.my

Received date: October 17, 2016; Accepted date: October 25, 2016; Published date: November 10, 2016

Copyright: ( 2016 Khajotia R, et al. This is an open-access article distributed under the terms of the Creative Commons Attribution License, which permits unrestricted use, distribution, and reproduction in any medium, provided the original author and source are credited.

\begin{abstract}
NIV is a form of ventilation which provides ventilator support through the patient's upper airways using a mask or other appropriate device. NIV is an effective treatment for patients with severe COPD. The beneficial effects of NIV have been particularly apparent in patients with acute hypercapnic respiratory failure (AHRF). BiPAP (Figure 1) and CPAP are the most common types of ventilators used in NIV, along with nasal masks and full-face masks.
\end{abstract}

Keywords: Non-invasive positive-pressure ventilation; Chronic obstructive pulmonary disease; Hypercapnic respiratory failure; Invasive mechanical ventilation

\section{Non-invasive positive-pressure ventilation (NIV)}

NIV is a form of ventilation which provides ventilator support through the patient's upper airways using a mask or other appropriate device. NIV is an effective treatment for patients with severe COPD. The beneficial effects of NIV have been particularly apparent in patients with acute hypercapnic respiratory failure (AHRF). BiPAP (Figure 1) and CPAP are the most common types of ventilators used in NIV, along with nasal masks and full-face masks.

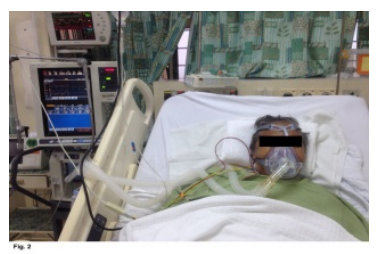

Figure 1: A 54-year-old patient with acute exacerbation of COPD on non-invasive ventilation (NIV), using BiPAP.

\section{Indications for NIV:}

- Prior to considering invasive ventilation via endotracheal intubation, NIV may be tried in patients with severe COPD who present with an acute exacerbation. It may also be the maximal treatment offered to patients who may not be appropriate candidates for future invasive ventilation.

- NIV may be indicated in patients with acute exacerbation of COPD who have persistent respiratory acidosis $\left(\mathrm{pH}<7.35, \mathrm{H}^{+}>45\right.$ $\mathrm{nmol} / \mathrm{l}$ ) despite full medical treatment and controlled oxygen therapy.
- NIV has also been shown to be useful in patients with decompensated obstructive sleep apnoea.

- NIV is useful in acute and acute-on-chronic hypercapnic respiratory failure in patients with chest wall deformity or neuromuscular disease.

- NIV can be used in patients with extensive pneumonia who become hypoxic and/or hypercapnic despite good medical management.

- NIV is useful for weaning patients from invasive ventilation, especially when conventional weaning methods are unsuccessful.

- NIV is sometimes useful in patients with respiratory acidosis $\left(\mathrm{pH}<7.35, \mathrm{H}^{+}>45 \mathrm{nmol} / \mathrm{l}\right)$ secondary to an acute exacerbation of bronchiectasis. However, excessive secretions may be a limiting factor in these patients.

- NIV has also been successfully used in patients with acute respiratory distress syndrome (ARDS) and postoperative and post transplantation respiratory failure, reducing intubation rates, ICU stay and the overall mortality rate.

A number of prospective, controlled trials have been conducted in patients with severe COPD. Many studies conducted in intensive care units [1-4] have shown that NIV is a good form of ventilator management and that the tracheal intubation rate is markedly reduced in these patients. In fact, in one study [5] most of the complications, including pneumonia, were attributed to intubation and invasive ventilation. Patients on NIV should be regularly assessed using a combination of clinical assessment, pulse oximetry and arterial blood gas measurements.

Clinical features that should be observed at regular intervals include patients comfort, mental state, heart rate, respiratory rate, chest wall movements, coordination of respiratory efforts with ventilation and the use of accessory muscles of respiration. Absence of chest wall movements indicates that alveolar ventilation is not improving. This could be due to incorrect ventilator settings, inadequate tidal volume or inflation pressure or leaks around the facial mask. In patients on successful treatment with NIV, there is usually a significant 
improvement in the level of breathlessness within 1-2 hours [5,6] along with an improvement in the mental state [7].

It has been observed that oxygen levels improve within 1-2 hours in patients on NIV who are responding to treatment $[5,8]$. Hence, regular monitoring of the $\mathrm{SaO}_{2}$ is recommended along with arterial blood gas measurements. The saturation should be kept between $85 \%-90 \%$ and supplemental oxygen may be used if necessary. Regular arterial blood gas analysis of the $\mathrm{pH}, \mathrm{PaCO}_{2}$ and $\mathrm{PaO}_{2}$ are also vitally important in the successful monitoring of patients on NIV.

The duration of treatment with NIV is variable. Unlike invasive ventilation, it is not continuously required. The patient may be switched off the ventilator for other treatment such as physiotherapy, nebulization or feeds. Some studies have shown that NIV should be given for 4-20 hours/day in the first 24 hours, while the total duration of treatment with NIV has been observed to vary between 1-21 days [8].

Studies suggest that patients on NIV should be ventilated for as many hours as possible and as may be clinically indicated and tolerated [9]. Weaning the patient from NIV depends on the patient's clinical condition and stability.

One study has suggested that the best mode of weaning is to reduce duration of ventilation according to clinical criteria, by reducing day ventilation at first, before nocturnal ventilation is reduced [10]. Some studies have suggested clinical parameters as criteria for weaning from NIV. The clinical criteria include a respiratory rate of $<24$ breaths $/ \mathrm{min}$, heart rate $<110$ beats $/ \mathrm{min}$, compensated $\mathrm{pH}>7.35\left(\mathrm{H}^{+}<45 \mathrm{nmol} / \mathrm{l}\right)$, and $\mathrm{SpO}_{2}>90 \%$ on $\mathrm{FiO}_{2}<4 \mathrm{l} / \mathrm{min}$ [5].

\section{Indications of failure of NIV in severe COPD}

Failure of NIV in a patient with severe COPD can be suspected if:

- There is a failure to relieve symptoms

- Deterioration in the patient's conscious level

- Worsening of the patient's overall general condition

- Deteriorating arterial blood gas levels

- Inability of the patient to coordinate with the ventilator

- Development of complications such as pneumothorax, nasal bridge erosion, or stagnation of tracheal secretions

\section{Indications for home NIV}

Patient's treated with NIV for acute respiratory failure can usually be weaned within a few days. If NIV is needed for more than one week after an acute episode, this is an indicator that long-term NIV may be needed. All patients treated with NIV should undergo lung function testing and arterial blood gas analysis on room air, before discharge from hospital. RCP guidelines suggest that if the pre-discharge arterial blood gas measurement shows a $\mathrm{PaO}_{2}$ of $<7.3 \mathrm{kPa}$ in patients with severe COPD, a repeat arterial blood analysis must be done after 3 weeks.

If hypoxemia persists, oxygen therapy is indicated and, at this stage, nocturnal NIV should be considered if the patient is hypercapnic while breathing room air or if the $\mathrm{PaCO}_{2}$ rises significantly with administration of oxygen therapy to correct the hypoxemia.

Long term domiciliary NIV should be considered in patients with COPD who have had three or more episodes of acute hypercapnic respiratory failure in the one previous year. Many different types of ventilators have been used to provide NIV in acute hypercapnic respiratory failure (AHRF). BiPAP's used for non-invasive assisted spontaneous breathing (pressure support) usually use two different pressures: inspiratory positive airway pressure (IPAP) to assist inspiration, and a lower expiratory positive airway pressure (EPAP). EPAP eliminates exhaled air through the expiratory port and encourages lung recruitment. The ventilator settings in a BiPAP include the mode which is either spontaneous or timed.

The IPAP pressure is usually ranged from $12-15 \mathrm{~cm} \mathrm{H}_{2} 0$ which may be increased up to $20 \mathrm{~cm} \mathrm{H}_{2} \mathrm{O}$, depending on patient response. The EPAP is set ranged $4-5 \mathrm{~cm} \mathrm{H}_{2} 0$. The backup rate is 15 breaths/minute and the backup I:E ratio is 1:3. Bi-level positive airway pressure support has now been accepted as the main mode of NIV therapy in AHRF. However, future studies need to be conducted which compare this mode of ventilation with pressure and volume-controlled ventilators (Table 1)

\begin{tabular}{|c|}
\hline Failure to wean patient from the NIV \\
\hline $\begin{array}{l}\text { COPD with: } \\
\text { - Recurrent acute hypercapnoeic respiratory failure (>3 episodes) requiring } \\
\text { treatment with NIV } \\
\text { - Intolerance of supplementary oxygen (because of severe } \mathrm{CO}_{2} \text { retention) } \\
\text { with symptomatic sleep disturbance }\end{array}$ \\
\hline $\begin{array}{l}\text { Acute hypercapnic respiratory failure secondary to: } \\
\text { - } \quad \text { Spinal cord lesion } \\
\text { - } \quad \text { Chest wall deformity (e.g. scoliosis, thoracoplasty) } \\
\text { - } \quad \text { Morbid obesity (BMl>30) } \\
\text { - } \quad \text { Neuromuscular diseases }\end{array}$ \\
\hline
\end{tabular}

Table 1: Indications for long-term NIV.

\section{Use of NIV while weaning patients from invasive ventilation}

Studies [11] have been conducted wherein patients who failed a 2hour T-piece trial following invasive ventilation were randomly distributed into 2 groups: one who was extubated and put on NIV and the other who were continued on invasive ventilation. Though similar weaning methods were employed in both groups of patients, there was a clear advantage in the group on NIV.

A larger percentage of patients on NIV were successfully weaned, with reduced duration of need for assisted ventilation, ICU stay, and mortality and ventilation-associated infections such as pneumonia.

Another randomized study [12] on 33 patients who failed the Tpiece trial showed that patients who received NIV could be extubated earlier than those who were continued on invasive ventilation. A patient with a tracheostomy tube in place can also be given noninvasive ventilator therapy. For this, the tube must be capped off with the cuff completely deflated. However, NIV is sometimes ineffective despite the cuff being completely deflated because there may be an insufficient gap between the tracheostomy tube and the tracheal wall. In such patients, NIV is more successful with a smaller uncuffed fenestrated tracheostomy tube in place.

\section{Contraindications for the use of NIV:}

- NIV is contraindicated in patients with recent upper gastrointestinal surgery, bowel obstruction, large volumes of respiratory secretions, severe, life-threatening hypoxemia, confusion, drowsiness and agitation. 
Citation: Khajotia R, Raman K, Khajotia K (2016) Managing Severe COPD: Addressing the Challenges with Latest Trends and Treatment Options (Part II: Non-Pharmacological Management). J Clin Respir Dis Care 2: 121. doi:10.4172/2472-1247.1000121

Page 3 of 9

- NIV should not be used in patients who have undergone recent facial or upper airway surgery, patients who have fixed obstruction of the upper airways, patients suffering from serious burns or facial trauma, and in severe vomiting.

- In patients with a pneumothorax, an intercostal drain should first be inserted before commencing NIA.

\section{Invasive mechanical ventilation}

In severe COPD, the majority of patients with acute respiratory failure should undergo a trial of non-invasive mechanical ventilation (NIV) as intubation may be successfully avoided and mortality reduced, since weaning off mechanical ventilation is difficult in these patients [13-15].

In patients with severe COPD, the primary aim of invasive mechanical ventilation is to correct the abnormalities in oxygen saturation and ventilation; reduce the work of breathing and prevent dynamic hyperinflation (DHI). Invasive mechanical ventilation is typically reserved as a last option of life support for acute respiratory failure in severe COPD. The patient may be intubated (Figure 2) or may require tracheostomy, if long-term mechanical ventilation is anticipated.

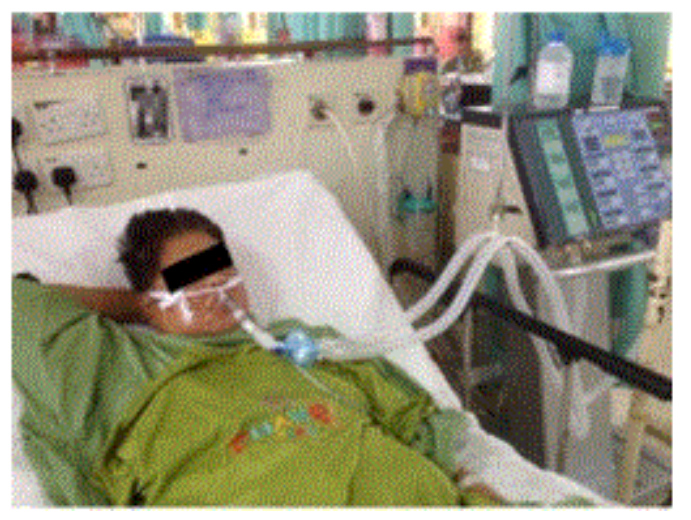

Figure 2: A 64-year-old patient with severe COPD and community acquired pneumonia requiring invasive ventilation via an endotracheal tube.

In one of our patients, long-term mechanical ventilation was needed and hence he had to undergo a tracheostomy (Figure 3). Following 6 weeks treatment with invasive mechanical ventilation through a tracheostomy tube, he was subsequently sent home on long-term oxygen therapy via the tracheostomy tube (Figure 3).

This was because repeated attempts at removing the tracheostomy tube were unsuccessful, and resulted in a significant fall in $\mathrm{PaO}_{2}$ and $\mathrm{SaO}_{2}$ levels, accompanied by nocturnal desaturation. Indications for invasive mechanical ventilation in patients with severe COPD are similar to those for all patients with acute respiratory failure.

However, in addition, the patient's preferences for life support have to be taken into account when intubation is planned, as the treatment on invasive ventilation is long drawn-out and weaning is going to be difficult. Clinical practice supports earlier intubation and ventilation before respiratory fatigue sets in, as delay in intubating a patient with respiratory fatigue and failure may lead to added complications like cardiogenic shock and circulatory collapse.

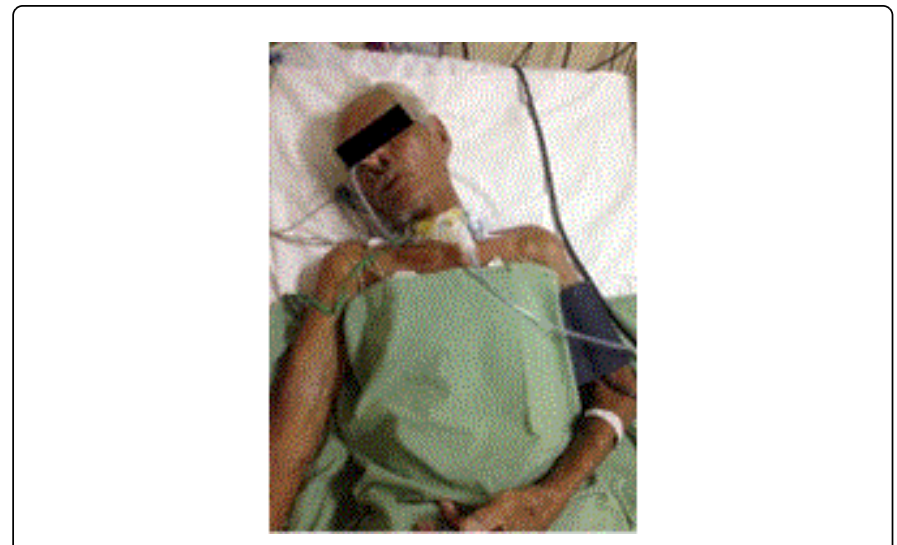

Figure 3: An 81-year-old patient with severe infective exacerbation of COPD and type II respiratory failure, on long-term invasive ventilation through a tracheostomy tube.

\section{Indications}

These include:

- NPPV failure with deterioration of ABG values and/or $\mathrm{pH}$ over 1-2 $\mathrm{h}$

- Lack of improvement in ABG values and/or $\mathrm{pH}$ after 4 hours on NIV

- Severe acidosis $(\mathrm{pH}<7.25)$ with $\mathrm{CO}_{2}$ retention $\left(\mathrm{PaCO}_{2}>8 \mathrm{kPa}(60\right.$ $\mathrm{mmHg}$ )

- Life-threatening hypoxemia

- $\mathrm{PaO}_{2}<92 \%$

- Severe respiratory distress

- Sustained tachypnea $>35$ breaths/min

- Use of accessory muscles of respiration

- Paradoxical motion of the rib cage, abdomen and subcostal angle

\section{Altered mental status}

These indications should prompt consideration for immediate intubation and mechanical ventilation [16,17]. However, when mixed acid-base disorders are present, the predicted $\mathrm{pH}$ for acute and chronic acidosis should be assessed to avoid unnecessary intubation for chronic conditions. A bedside scoring system, BAP-65, that uses signs of respiratory distress, along with other risk factors, has also been found useful in predicting when mechanical ventilation is needed, and may be used in patients with severe COPD $[18,19]$.

Several studies in patients with severe COPD who are on NIV have shown that deteriorating or unaltered gas exchange is a strong indicator for mechanical ventilation $[20,21]$. Hence, a timely escalation in the level of care from non-invasive to invasive ventilation can be achieved; if evaluation of the patient's clinical condition is conducted at two-hourly intervals.

The commonly used ventilator modes are volume-limited modes of ventilation, while pressure support or pressure-limited modes are less suitable for patients with airflow limitation. Although the optimal mode is unknown, typically the following volume-limited modes are used: assist control ventilation (ACV), synchronized intermittent mandatory ventilation (IMV) or SIMV with pressure support 
ventilation (SIMV/PSV). Switching modes is not uncommon particularly when complications of mechanical ventilation occur. Among all modes, the work of breathing is lowest in patients receiving Assist Control Ventilation (ACV) [22,23]. However, the work of breathing on this mode can still be excessively high if the patient is not adequately sedated, is not synchronizing with the ventilator, or has excessively high inspiratory flow rates [24,25]. Compared to ACV, synchronized intermittent mandatory ventilation (SIMV) has been shown to be associated with greater work of breathing $[25,26]$. Notably, when patients have stabilized and liberation from mechanical ventilation is being planned, using IMV may be considered.

In pressure-support ventilation (PSV), the volume of spontaneous breaths is augmented with a pre-set amount of pressure and all breaths are patient triggered. However, the incremental benefit diminishes at higher levels of pressure support (>60 percent of patient effort) [22,23]. Consistent with this observation, patients with COPD can become more dyssynchronous with the ventilator when higher levels of PSV are used [27]. PSV is infrequently used to ventilate patients with COPD. This is, in part, because a predetermined minute volume cannot be set, and reduced work of breathing is not guaranteed with this mode, both of which are desirable in COPD [22,23]. In addition, minute ventilation may be insufficient during PSV in patients with COPD because airway resistance is high. High airway resistance results in decreased airflow during inspiration causing inspiration to be terminated early before the optimal tidal volume has been delivered [28]. PSV also does little to decrease auto-PEEP (the product of dynamic hyperinflation), which, when left untreated, can increase work of breathing and lead to barotrauma and death [29].

Pressure-limited modes of ventilation are modes in which ventilator-assisted breaths are triggered by the patient and a set pressure is delivered. This mode is infrequently used in patients with COPD and is usually reserved as a rescue mode when peak inspiratory pressures or plateau pressures are uncontrollably high in patients with ARDS. Increased level of intrinsic positive end-expiratory pressure (PEEPi or "auto-PEEP") leads to dynamic hyperinflation (DHI). DHI elevates auto-PEEP levels thereby causing patient-ventilator dyssynchrony and increased work of breathing, which may lead to barotrauma, cardiovascular collapse, and death. In a prospective study of 13 patients with COPD who were being mechanically ventilated, all the patients had measurable auto-PEEP (mean $9.4 \mathrm{~cm}$ $\mathrm{H}_{2} \mathrm{O}$ ), and seven had an auto-PEEP greater than $10 \mathrm{~cm} \mathrm{H}_{2} \mathrm{O}$ [30]. It was therefore concluded that auto-PEEP is responsible for up to onethird of the total work of breathing in patients with COPD, who are mechanically ventilated [31]. Auto-PEEP can be assessed in a number of ways. One practical and reliable method in patients with COPD is the demonstration on ventilator graphics of a progressive rise in peak airway pressures during mandatory tidal volume ventilation $[32,33]$. While auto-PEEP can be quantitatively assessed by measuring airway opening pressure during an end-expiratory pause (Paw), this method is only accurate when the patient is paralyzed or exhibiting negligible abdominal and chest wall muscle engagement during exhalation, which is uncommon in COPD. Significant complications of DHI such as barotrauma can prolong the course of mechanical ventilation and result in cardiovascular collapse or death. Thus prevention of DHI is especially important in this population.

The prevention and treatment of DHI in patients with COPD who are mechanically ventilated is by reducing the respiratory rate and/ or tidal volume, raising the inspiratory flow rate and treating the underlying airflow obstruction when present. In addition, the application of extrinsic PEEP can reduce the work of breathing (WOB) and improve patient-ventilator synchrony through a reduction in ineffective triggering attempts by the patient [34]. Thus, the simultaneous manipulation of settings to achieve this balance should reduce ventilator dyssynchrony and work of breathing as well as decrease auto-PEEP and its attendant complications [35].

When treating mechanically ventilated COPD patients with DHI, the following should be considered:

- Reduce minute ventilation and prolong expiratory time: because the main determinants of auto-PEEP are minute ventilation (Ve) and expiratory time (Te), the key strategies to limiting auto-PEEP focus on reducing total Ve, prolonging expiratory time, and improving expiratory flow [36,37].

- Adjust inspiratory trigger sensitivity to reduce ineffective triggering and lower the work of breathing: in patients with COPD ineffective triggering and consequently high work of breathing (WOB) and dyssynchrony are common. Mitigating patientventilator dyssynchrony and WOB relies primarily upon optimizing the trigger sensitivity for inspiration [38]. In patients with COPD, ineffective triggering can be reduced by making sure the patient's intrinsic inspiratory time closely matches the duration of the tidal breath delivered by the ventilator in order to avoid active exhalation against the machine-driven breath. Inspiratory work can be reduced by adjusting the trigger sensitivity (usually flow triggered) to the lowest level needed to initiate a breath, yet high enough to avoid over ventilation (also known as "autocycling") $[39,40]$.

- Applying extrinsic PEEP: In patients mechanically ventilated with COPD, the application of extrinsic PEEP has been shown to decrease WOB and improve patient-ventilator synchrony although it may not decrease DHI $[41,42]$.

Although DHI can be prevented and treated, occasionally COPD patients on auto-PEEP present with life-threatening cardiovascular collapse from reduced venous return. When acute hypotension develops in the setting of a rapid breathing rate or rising peak airway pressures, severe auto-PEEP should be suspected. A potentially lifesaving maneuver would be the immediate disconnection of the endotracheal tube from the ventilator. The prognosis for mechanically ventilated patients with COPD is associated with high rates of Intensive Care Unit (ICU) mortality (37\% to 64\%) [43,44]. Unfortunately, the ability of patients with COPD to be successfully liberated from mechanical ventilation has been poorly studied [45]. Failure of noninvasive ventilation, the presence of multi organ failure and virulent pathogens such as Pseudomonas and Aspergillus spp are poor prognostic factors in this population. In earlier studies mortality was determined by the severity of the underlying disease (example multi organ failure, Acute Respiratory Distress Syndrome (ARDS), and high Acute Physiologic and Chronic Health Evaluation [APACHE] score). However, several studies have since reported that a diagnosis of COPD alone is also a risk factor for death in mechanically ventilated patients. In one retrospective study of 428 patients with acute respiratory failure due to community acquired pneumonia, compared to patients without COPD, patients with COPD had a higher rate of requiring mechanical ventilation (odds ratio [OR] 2.78, 95\% CI 1.6-4.7) and of dying (OR 1.58, 95\% CI 1.0-1.4) [44] and intubated patients with COPD who had failed noninvasive ventilation was observed to have the highest mortality (50\%). In another prospective observational study of 235 patients who were mechanically ventilated for respiratory failure, compared to patients without a diagnosis of 
COPD, a diagnosis of COPD was an independent predictor of mortality (hazard ratio, 2.1 ; 95\% CI 1.1-3.9) [46].

In two observational studies of patients with ventilator-associated pneumonia, compared to patients without COPD, patients with COPD had higher rates of ICU mortality (64 versus $28 \%$ ), and a longer duration of mechanical ventilation (24 versus 13 days) and ICU stay (26 versus 15 days) $[47,48]$. Infection with emerging pathogens, such as Pseudomonas and Aspergillus spp, may also be associated with high mortality in patients mechanically ventilated for acute respiratory failure and COPD [49]. The emergence of these organisms in COPD may be in part due to the high rate of initial empiric antibiotic and glucocorticoid therapy that is common in this patient population [50,51]. In particular, when infection with Aspergillus spp is detected and treated late in its course, the mortality is thought to range from 80 to $100 \%[52]$.

\section{Post-hypercapnoeic metabolic alkalosis in patients on invasive mechanical ventilation}

A severe COPD with type II respiratory failure has chronically elevated $\mathrm{PaCO}_{2}$ levels. In order to keep the $\mathrm{pH}$ to near normal levels, renal compensation occurs resulting in chronically elevated $\mathrm{HCO}_{3}$ levels in the blood. When such a patient is admitted to the ICU in a drowsy or unconscious state and put on invasive mechanical ventilation, the temptation to rapidly lower the $\mathrm{PaCO}_{2}$ levels to nearnormal levels by giving a high ventilator rate must be resisted. This is because when an attempt is made to rapidly bring down the carbon dioxide levels by increasing the ventilator rate, the $\mathrm{PaCO}_{2}$ reduces rapidly leaving little time for metabolic compensation to set in. Hence, the patient develops severe post-hypercapnoeic metabolic alkalosis [53] which can increase myocardial muscle irritability, leading to arrhythmias and decreased myocardial contractility. Therefore, in COPD patients with type II respiratory failure, who are on invasive mechanical ventilation, the $\mathrm{PaCO}_{2}$ levels should be gradually reduced, [53] giving ample time for metabolic compensation to set in, thus preventing severe metabolic alkalosis from occurring.

\section{Tracheobronchial mucus plugging in patients on invasive mechanical ventilation}

Thick, viscid mucus plugging the large airways is a common problem encountered in COPD patients on mechanical ventilation. This can lead to segmental or lobar atelectasis, hypoxemia hypercapnea and acute respiratory distress. Usually, it is initially suspected by the intensivist when the ventilatory pressure levels start rising to unreasonably high levels and there is diminished air entry, accompanied by respiratory distress and deterioration in blood gas levels. Treatment usually consists of using mucolytic agents through the endotracheal or tracheostomy tube at regular intervals, accompanied by adequate hydration, good nursing care and regular chest physiotherapy. Dornase alfa (DNase) inhalation solution or 2-3 drops of sodium bicarbonate solution administered through the endotracheal or tracheostomy tube are both mucolytic agents which helps to liquefy thick secretions and facilitate their removal. N-acetyl cysteine aerosols may also be administered in an effort to promote clearance of tenacious secretions. However, the efficacy of $\mathrm{N}$-acetyl cysteine has not yet been documented. Moreover, $\mathrm{N}$-acetyl cysteine may cause acute bronchoconstriction. Hence some clinicians recommend its use to be limited to direct instillation at the time of fiber optic bronchoscopy for clearance of extensive mucus impaction. Overall, mucus impaction is a serious problem in COPD patients on mechanical ventilation, which needs to be suspected early and treated promptly.

\section{Home Mechanical Ventilation by Tracheostomy (HMVT)}

HMVT has been used in patients with severe and advanced COPD. However, the long-term benefit of HMVT in severe COPD compared with long-term oxygen therapy (LTOT) is difficult to evaluate because of a paucity of prospective and controlled studies. A French multicenter study group [54] researched the long-term survival and prognostic factors of 259 patients with severe COPD, who had a tracheostomy tube for at least a period of 1 year. $78 \%$ of the patients die by the end of the study period. The survival rate for the study population was $70 \%$ at 2 years, $44 \%$ at 5 years, and $20 \%$ at 10 years. The factors which favorably impacted survival for more than 5 years were age $<65$ years, use of an uncuffed tube, and $\mathrm{PaO}_{2}$ levels $>55 \mathrm{~mm}$ $\mathrm{Hg}$ while breathing room air, during the 3 months following tracheostomy $(\mathrm{p}<0.01)$. This study indicates the favorable outcome of HMVT in severe COPD. However, further studies should be conducted regarding the role of permanent tracheostomy in the longterm prognosis of severe COPD patients.

\section{Nutrition}

Mortality rates are greatly increased in below body-weight patients with severe COPD than in overweight and obese COPD patients $[55,56]$. Malnutrition in hospitalized patients with severe COPD is commonly seen but is rarely recognized in a timely manner. Depleted nutritional levels are commonly observed in patients with severe COPD. It is mainly due to an imbalance between low-energy caloric intake and high-energy requirements, [57] causing respiratory muscle wasting and increased work of breathing [58]. Consequently, lack of proper nutritional support is associated with a poor prognosis in severe COPD [59,60].

Studies [61] have shown that chronically ventilated COPD patients with type II respiratory failure who had a body mass index (BMI) less than 20 had increased morbidity and mortality. Studies have shown reduced survival rates in COPD patients with significant intercostal and accessory muscle wasting while an increase in body weight and muscle mass has been shown to result in better exercise tolerance, improved survival rates and reduced mortality [62]. Hence, an assessment of the nutritional status is vitally important in the treatment of patients with severe COPD. Moreover, this is especially critical while weaning chronically ventilated COPD patients off mechanical ventilation. Enteral nutrition using oral nutritional supplements (ONS) or by Ryle's tube feeding (RTF) enables adequate nutritional intake to be maintained when normal intake is inadequate. In COPD patients, adequate enteral nutrition may therefore be necessary to improve the nutritional status of the patient and improve respiratory muscle function. Frequent ONS in small quantities is preferred, in order to avoid postprandial breathlessness and improve compliance [63].

\section{Pulmonary Rehabilitation}

As the severity of COPD worsens the patient becomes increasingly breathless and consequently more bed-bound. This results in depression, increasing social isolation [64] and muscular and cardiovascular deterioration. The primary aim of pulmonary rehabilitation is to retard the process of cardiovascular and muscular deterioration. For this, a well-designed pulmonary rehabilitation 
program needs to be drawn up which would cater to the particular needs of every individual patient. This includes aerobic physical training, behavior modification, psychosocial counseling, exercise, comprehensive education, physiotherapy and nutritional support, in order to improve the quality of life and work tolerance in patients with severe COPD [65]. These patients are normally advised to attend pulmonary rehabilitation programs thrice a week, with each session lasting 3 to 4 hours. However, major factors preventing patient attendance at these programs include increasing severity of breathlessness, inability to walk, severe depression, severe cardiovascular function impairment, and major cognitive dysfunction [66].

A number of studies have been done on the advantages of pulmonary rehabilitation in patients with severe COPD. One such study concluded that pulmonary rehabilitation programs improved the quality of life and work tolerance [66]. Regular pulmonary rehabilitation has also been shown to reduce the frequency of respiratory-related hospital admissions [67], lessen the perception of breathlessness in the patient, decrease the level of anxiety and depression, improve respiratory muscle strength and consequently improve survival in patients with severe COPD. However, it has also been shown that if the program is not sustained, the improvement in the patient's condition begins to erode substantially in the following years [67].

\section{Surgical management in severe COPD}

A major surgical option is lung-volume reduction surgery in selected patients with severe COPD. This involves surgical resection of severely emphysematous parts of the lung, thereby allowing the remaining lung tissue to expand and function more normally, resulting in improved ventilatory function, improved mechanical efficiency of the inspiratory muscles, increased exercise capacity and better quality of life $[68,69]$. However, in a randomized trial in patients with severe COPD, lung-volume reduction surgery has not been associated with a reduction in mortality, as compared with conservative medical management [70]. Careful selection of patients is essential for optimal post-operative results. Patients with predominant upper-lobe emphysema appear to do best postoperatively. Following surgery, there is an increase in $\mathrm{FEV}_{1}$, reduction in the total lung capacity (TLC) and functional residual capacity (FRC), improved work of breathing, improved exercise capacity, and improved quality of life [71,72]. Though overall mortality has not been shown to improve postoperatively, the mortality rate actually increased in patients with preoperative severe obstructive impairment (i.e. $\mathrm{FEV}_{1} \leq 20 \%$ of the predicted normal value) and a reduction in the diffusion capacity for carbon monoxide to $<20 \%$ of the predicted normal value [73].

Single-lung transplantation is another option that offers severely disabled patients with end-stage emphysema $\left(\mathrm{FEV}_{1}\right.$ less than $25 \%$ of the predicted normal value after the administration of a bronchodilator), who have such complications as pulmonary hypertension, moderate to severe hypoxemia, and hypercapnia [74], to resume normal daily activities. However, the median survival rate after single-lung transplantation is far lesser (about 5 years) than after transplantation of other organs [75]. Moreover, the surgery does not appear to significantly improve survival in patients with severe COPD as compared to routine medical treatment [76].

\section{Vaccination}

There is little evidence that vaccination is beneficial in patients with COPD. Even so, annual influenza vaccination and pneumococcal vaccination should be given to all patients in an effort to reduce both morbidity and mortality [77,78]. In addition, use of influenza vaccine does not appear to increase the incidence of adverse reactions in patients with severe COPD [79]. Inactivated influenza vaccine is given to all patients with severe COPD excepting those who are allergic to any component of the vaccine. It is administered annually before the commencement of the influenza season or at any time during the season. Trials have shown a reduction in influenza-related respiratory illnesses [80] and hospital admissions, as well as a reduction in mortality during the influenza season [81]. A polysaccharide pneumococcal vaccine is administered to all patients with severe COPD except those who may be hypersensitive to any component of the vaccine. In patients less than 65 years of age, the vaccine is administered once or twice in a lifetime, while patients who are more than 65 years of age must be revaccinated if they have been vaccinated $>5$ years earlier and were less than 65 years of age at the time of the primary vaccination. Data from a meta-analysis [82] have shown no reduction in exacerbations in patients with severe COPD who were administered the pneumococcal vaccine. However, one study [83] showed a significant reduction in hospitalization for pneumonia and a significant fall in mortality in patients with chronic lung disease, who were administered the pneumococcal vaccine.

\section{End-of-life Decision-making}

Patients with COPD have a poor quality of life, impaired emotional well-being, and a limited life expectancy. Active participation of COPD patients in decision-making regarding their care and treatment promotes patient autonomy as a fundamental ethical principle, even though most medical treatment systems basically recognize that there are limitations in the treatment of such patients and medical care givers including physicians need not pursue unnecessary therapy [84]. Methods to facilitate proper decision-making if effectively developed can be highly effective. These methods can increase patients knowledge regarding their condition, improve the patient perception regarding the amount of benefit that may be obtained from a particular treatment, reduce conflict in the decision-making process and decrease indecision among patients regarding their choices and available options. Dales et al. [85] have developed an instrument to determine patient preferences for intubation and invasive mechanical ventilation. It consists of an audiotape and a brochure describing the process of intubation and mechanical ventilation and the possible long-term prognosis. In this study 20 advanced COPD patients (10 male, 10 female) effectively reached a decision regarding their long-term management. Moreover, the patients and their physicians concurred on their choices in $65 \%$ of cases. The study revealed that females were more averse to undergoing invasive mechanical ventilation than males. However, in this study there was no agreement on choices between patients and their surrogate decision-makers.

\section{Advance Directives}

Advance directives can work reasonably well for COPD patients and are encouraged, in order to increase patient autonomy and allow control over care by deciding treatment options and appointing surrogate decision-makers, in the event the patient is unable to decide on the further course of treatment later on, example: while on 
mechanical ventilation. Not more than $30 \%$ Americans make advance directives and in most other countries this rate is much lower [86]. Unlike in COPD, advance directives work better in conditions where the disease course is well-charted, as in amyotrophic lateral sclerosis (ALS). Hence, it can be problematic in patients with severe COPD who are being treated in an ICU. Sometimes the directives are too ambiguous to be meaningful or too treatment-centric to be practically applicable. Moreover, though the directives are supposed to be based on patient autonomy, in some cultures decisions are made by elders in the family or are based on cultural beliefs. In spite of all these drawbacks, advance directives can work well in patients with severe COPD if there is clarity regarding its use and applicability.

\section{References}

1. Miravitlles M, Murio C, Guerrero T, Gisbert R (2002) Pharmacoeconomic evaluation of acute exacerbations of chronic bronchitis and COPD. Chest 121: 1449-1455.

2. Martin TJ, Hovis JD, Costantino JP, Bierman MI, Donahoe MP, et al. (2000) A randomized, prospective evaluation of noninvasive ventilation for acute respiratory failure. Am J Respir Crit Care Med 161: 807-813.

3. Brochard L, Mancebo J, Wysocki M, Lofaso F, Conti G et al. (1995) Noninvasive ventilation for acute exacerbations of chronic obstructive pulmonary disease. N Engl J Med 333: 817-822.

4. Celikel T, Sungur M, Ceyhan B, Karakurt S (1998) Comparison of noninvasive positive pressure ventilation with standard medical therapy in hypercapnic acute respiratory failure. Chest 14: 1636-1642.

5. Kramer N, Meyer TJ, Meharg J, Cece RD, Hill NS (1995) Randomized, prospective trial of noninvasive positive pressure ventilation in acute respiratory failure. Am J Respir Crit Care Med 151: 1799-1806.

6. Conway J, Hitchcock R, Godfrey RC, Carroll MP (1993) Nasal intermittent positive pressure ventilation in acute exacerbations of chronic obstructive pulmonary disease: a preliminary study. Respir Med 87: 387-394.

7. Wysocki M, Tric L, Wolff MA, Millet H, Herman B (1995) Noninvasive pressure support ventilation in patients with acute respiratory failure. A randomized comparison with conventional therapy. Chest 107: 761-768.

8. Benhamou D, Girault C, Faure C, Portier F, Muir JF (1992) Nasal mask ventilation in acute respiratory failure: experience in elderly patients. Chest 102: 912-917.

9. Meyer T, Hill N (1994) Noninvasive positive pressure ventilation to treat respiratory failure. Ann Intern Med 120: 760-770.

10. Brown J, D Jones, Mikelsons C (1998) Using nasal intermittent positive pressure ventilation on a general respiratory ward. J R Coll Physicians Lond 32: 219-224.

11. Nava S, Ambrosino N, Clini E, Prato M, Orlando G, et al. (1998) Noninvasive mechanical ventilation in the weaning of patients with respiratory failure due to chronic obstructive pulmonary disease. A randomized, controlled trial. Ann Intern Med 128: 721-728.

12. Girault C, Daudenthun I, Chevron V, Tamion F, Leroy J, et al. (1999) Non-invasive ventilation as a systematic extubation and weaning technique in acute-on-chronic respiratory failure. Am J Respir Crit Care Med 160: 86-92.

13. Celli BR, MacNee W, A Agusti, A Anzueto, B Berg, et al. (2004) Standards for the diagnosis and treatment of patients with COPD: a summary of the ATS/ERS position paper. Eur Respir J 23: 932-946.

14. Evans TW (2001) International Consensus Conferences in Intensive Care Medicine: non-invasive positive pressure ventilation in acute respiratory failure. Organised jointly by the American Thoracic Society, the European Respiratory Society, the European Society of Intensive Care Medicine, and the Société de Réanimation de Langue Française, and approved by the ATS Board of Directors, December 2000. Intensive Care Med 27: 166-178.

15. Slutsky AS (1993) Mechanical ventilation. American College of Chest Physicians Consensus Conference. Chest 104: 1833-1859.
16. Tobin MJ, Perez W, Guenther SM, Lodato RF, Dantzker DR (1985) Does rib cage-abdominal paradox signify respiratory muscle fatigue? J Appl Physiol 63: 851-860.

17. Shorr AF, Sun X, Johannes RS, Yaitanes A, Tabak YP (2011) Validation of a novel risk score for severity of illness in acute exacerbations of COPD. Chest 140: 1177-1183.

18. Tabak YP, Sun X, Johannes RS, Gupta V, Shorr AF (2009) Mortality and need for mechanical ventilation in acute exacerbations of chronic obstructive pulmonary disease: development and validation of a simple risk score. Arch Intern Med 169: 1595-1602.

19. Phua J, Kong K, Lee KH, Shen L, Lim TK (2005) Noninvasive ventilation in hypercapnic acute respiratory failure due to chronic obstructive pulmonary disease vs. other conditions: effectiveness and predictors of failure. Intensive Care Med 31: 533-539.

20. Carratù P, Bonfitto P, Dragonieri S, Schettini F, Clemente R, et al. (2005) Early and late failure of noninvasive ventilation in chronic obstructive pulmonary disease with acute exacerbation. Eur J Clin Invest 35: 404-409.

21. Leung P, Jubran A, Tobin MJ (1997) Comparison of assisted ventilator modes on triggering, patient effort, and dyspnea. Am J Respir Crit Care Med 155: 1940-1948.

22. Tobin MJ, Jubran A, Laghi F (2001) Patient-ventilator interaction. Am J Respir Crit Care Med 163: 1059-1063.

23. Ward ME, Corbeil C, Gibbons W, Newman S, Macklem PT (1988) Optimization of respiratory muscle relaxation during mechanical ventilation. Anesthesiology 69: 29-35.

24. Marini JJ, Smith TC, Lamb VJ (1988) External work output and force generation during synchronized intermittent mechanical ventilation. Effect of machine assistance on breathing effort. Am Rev Respir Dis 138: 1169-1179.

25. Imsand C, Feihl F, Perret C, Fitting JW (1994) Regulation of inspiratory neuromuscular output during synchronized intermittent mechanical ventilation. Anesthesiology 80: 13-22.

26. Parthasarathy S, Jubran A, Tobin MJ (1998) Cycling of inspiratory and expiratory muscle groups with the ventilator in airflow limitation. Am J Respir Crit Care Med 158: 1471-1478.

27. Marini JJ, Crooke PS, Truwit JD (1989) Determinants of pressure-preset ventilation: A mathematical model of pressure control. J Appl Physiol 67: 1081-1092.

28. Jubran A, Van de Graaff WB, Tobin MJ (1995) Variability of patientventilator interaction with pressure support ventilation in patients with chronic obstructive pulmonary disease. Am J Respir Crit Care Med 152: $129-136$

29. MacIntyre NR, Cheng KC, McConnell R (1997) Applied PEEP during pressure support reduces the inspiratory threshold load of intrinsic PEEP. Chest 111: 188-193.

30. Coussa ML, Guérin C, Eissa NT, Corbeil C, Chassé M, et al. (1993) Partitioning of work of breathing in mechanically ventilated COPD patients. J Appl Physiol 75: 1711-1719.

31. Thorevska NY, Manthous Cam (2004) Determinants of dynamic hyperinflation in a bench model. Respir Care 49: 1326-1334.

32. Petrof BJ, Legaré M, Goldberg P, Milic-Emili J, Gottfried SB (1990) Continuous positive airway pressure reduces work of breathing and dyspnea during weaning from mechanical ventilation in severe chronic obstructive pulmonary disease. Am Rev Respir Dis 141: 281-289.

33. Caramez MP, Borges JB, Tucci MR, Okamoto VN, Carvalho CR, et al. (2005) Paradoxical responses to positive end-expiratory pressure in patients with airway obstruction during controlled ventilation. Crit Care Med 33: 1519-1528.

34. Ranieri VM, Mascia L, Petruzzelli V, Bruno F, Brienza A, et al. (1995) Inspiratory effort and measurement of dynamic intrinsic PEEP in COPD patients: effects of ventilator triggering systems. Intensive Care Med 21: 896-903.

35. Marini JJ, Brower RG (2003) Auto-peep with low tidal volume. Am J Respir Crit Care Med 167: 1150-1151. 
36. Marini JJ, Crooke PS (1993) A general mathematical model for respiratory dynamics relevant to the clinical setting. Am Rev Respir Dis 147: 14-24.

37. Marini JJ, Rodriguez RM, Lamb V (1986) The inspiratory workload of patient-initiated mechanical ventilation. Am Rev Respir Dis 134: 902.

38. Polese G, Massara A, Poggi R, Brandolese R, Brandi G, et al. (1995) Flowtriggering reduces inspiratory effort during weaning from mechanical ventilation. Intensive Care Med 21: 682-686.

39. Sassoon CS, Lodia R, Rheeman CH, Kuei JH, Light RW, et al. Inspiratory muscle work of breathing during flow-by, demand-flow, and continuousflow systems in patients with chronic obstructive pulmonary disease. Am Rev Respir Dis 145: 1219-1222.

40. Smith TC, Marini JJ (1985) Impact of PEEP on lung mechanics and work of breathing in severe airflow obstruction. J Appl Physiol 65: 1488-1499.

41. Ranieri VM, Giuliani R, Cinnella G, Pesce C, Brienza N, et al. (1993) Physiologic effects of positive end-expiratory pressure in patients with chronic obstructive pulmonary disease during acute ventilatory failure and controlled mechanical ventilation. Am Rev Respir Dis 147: 5-13.

42. Seneff MG, Wagner DP, Wagner RP, Zimmerman JE, Knaus WA (1995) Hospital and 1-year survival of patients admitted to intensive care units with acute exacerbation of chronic obstructive pulmonary disease. JAMA 274: 1852-1857.

43. Rello J, Rodriguez A, Torres A, Roig J, Sole-Violan J, et al. (2006) Implications of COPD in patients admitted to the intensive care unit by community-acquired pneumonia. Eur Respir J 27: 1210-1216.

44. Peñuelas O, Frutos-Vivar F, Fernández C, Anzueto A, Epstein SK, et al. (2011) Characteristics and outcomes of ventilated patients according to time to liberation from mechanical ventilation. Am J Respir Crit Care Med 184: 430-437.

45. Rodríguez A, Lisboa T, Solé-Violán J, Gómez F, Roca O, et al. (2011) Impact of nonexacerbated COPD on mortality in critically ill patients. Chest 139: 1354-1360.

46. Makris D, Desrousseaux B, Zakynthinos E, Durocher A, Nseir S (2011) The impact of COPD on ICU mortality in patients with ventilatorassociated pneumonia. Respir Med 105: 1022-1029.

47. Nseir S, Di Pompeo C, Soubrier S, Béatrice Cavestri, Elsa Jozefowicz, et al. (2005) Impact of ventilator-associated pneumonia on outcome in patients with COPD. Chest 128: 1650-1656.

48. Fernández-Ruiz M, Silva JT, San-Juan R, de Dios B, García-Luján R, et al. (2012) Aspergillus tracheobronchitis: report of 8 cases and review of the literature. Medicine 91: 261-273.

49. Vogeser M, Wanders A, Haas A, Ruckdeschel G (1999) A four-year review of fatal Aspergillosis. Eur J Clin Microbiol Infect Dis 18: 42-45.

50. Agustí C, Rañó A, Filella X, González J, Moreno A, et al (2003) Pulmonary infiltrates in patients receiving long-term glucocorticoid treatment: etiology, prognostic factors, and associated inflammatory response. Chest 123: 488-498.

51. Bulpa PA, Dive AM, Garrino MG, Delos MA, Gonzalez MR, et al. (2001) Chronic obstructive pulmonary disease patients with invasive pulmonary aspergillosis: benefits of intensive care? Intensive Care Med 27: 59-67.

52. Khajotia R (2008) Ventilatory management in a patient with chronic obstructive pulmonary disease: A need for caution. Malays Fam Physician 3: 166-167.

53. Muir JF, Girault C, Cardinaud JP, Polu JM (1994) Survival and long-term follow-up of tracheostomized patients with COPD treated by home mechanical ventilation. A multicenter French study in 259 patients. French Cooperative Study Group. Chest 106: 201-209.

54. Landbo C, Prescott E, Lange P, Vestbo J, Almdal TP (1999) Prognostic value of nutritional status in chronic obstructive pulmonary disease. Am J Respir Crit Care Med 160: 1856-1861.

55. Prescott E, Almdal T, Mikkelsen KL, Tofteng CL, Vestbo J, et al. (2002) Prognostic value of weight change in chronic obstructive pulmonary disease: results from the Copenhagen City Heart Study. Eur Respir J 20: 539-544.
56. Debigarè $\mathrm{R}$, Cote $\mathrm{CH}$, Maltais $\mathrm{F}$ (2001) Peripheral muscle wasting in Chronic Obstructive Pulmonary Disease. Am J Respir Crit Care Med 164: 1712-1717.

57. Wouters EFM (2002) Chronic obstructive pulmonary disease. Systemic effects of COPD. Thorax 57: 1067-1070.

58. Anthonisen NR, Wright EC, Hodgkin JE (1986) Prognosis in chronic obstructive pulmonary disease. Am Rev Respir Dis 133: 14-20.

59. Schols AM, Slangen J, Volovics L, Wouters EF (1998) Weight loss is a reversible factor in the prognosis of chronic obstructive pulmonary disease. Am J Respir Crit Care Med 157: 1791-1797.

60. Sivasothy P, Smith IE, Shneerson JM (1998) Mask intermittent positive pressure ventilation in chronic hypercapnic respiratory failure due to chronic obstructive pulmonary disease. Eur Respir J 11: 34-40.

61. Cote CG, Celli BR (2005) Pulmonary rehabilitation and the BODE index in COPD. Eur Respir J 26: 630-636.

62. Anker SD, John M, Pedersen PU, Raguso C, Cicoira M, et al. (2006) ESPEN guidelines on enteral nutrition: cardiology and pulmonology. Clin Nutr 25: 311-318.

63. Schane RE, Walter LC, Dinno A, Covinsky KE, Woodruff PG (2008) Prevalence and risk factors for depressive symptoms in persons with chronic obstructive pulmonary disease. J Gen Intern Med 23: 1757-1762.

64. Lacasse Y, Wong E, Guyatt GH, King D, Cook DJ, et al. (1996) Metaanalysis of respiratory rehabilitation in chronic obstructive pulmonary disease. Lancet 348: 1115-1119.

65. Lacasse Y, Goldstein R, Lasserson TJ, Martin S (2006) Pulmonary rehabilitation for chronic obstructive pulmonary disease. Cochrane Database Syst Rev 4: CD003793.

66. Griffiths TL, Burr ML, Campbell IA, Lewis-Jenkins V, Mullins J, et al. (2000) Results at 1 year of outpatient multidisciplinary pulmonary rehabilitation: a randomised controlled trial. Lancet 355: 362-368.

67. Doyle RL, Mark JB (1998) Lung volume reduction surgery for the treatment of chronic obstructive pulmonary disease. Adv Intern Med 43: 233-252.

68. Geddes D, Davies M, Koyama H, David Hansell, Ugo Pastorino, et al. (2000) Effect of lung-volume-reduction surgery in patients with severe emphysema. N Engl J Med 343: 239-245.

69. National Emphysema Treatment Trial Research Group (2003) A randomized trial comparing lung-volume-reduction surgery with medical therapy for severe emphysema. N Engl J Med 48: 2059-2073.

70. Cooper JD, Patterson GA, Sundaresan RS, Trulock EP, Yusen RD, et al. (1996) Results of 150 consecutive bilateral lung volume reduction procedures in patients with severe emphysema. J Thorac Cardiovasc Surg 112: 1319-1329.

71. Criner GJ, Cordova FC, Furukawa S, Kuzma AM, Travaline JM, et al. (1999) Prospective randomized trial comparing bilateral lung volume reduction surgery to pulmonary rehabilitation in severe chronic obstructive pulmonary disease. Am J Respir Crit Care Med 160: 2018-2027.

72. National Emphysema Treatment Trial Research Group (2001) Patients at high risk of death after lung-volume-reduction surgery. N Engl J Med 345: 1075-1083.

73. Arcasoy SM, Kotloff RM (1999) Lung transplantation. N Engl J Med 340: 1081-1091.

74. Stavem K, Bjortuft O, Borgan O, Geiran O, Boe J (2006) Lung transplantation in patients with chronic obstructive pulmonary disease in a national cohort is without obvious survival benefit. J Heart Lung Transplant 25: 75-84.

75. Hosenpud JD, Bennett LE, Keck BM, Edwards EB, Novick RJ (1998) Effect of diagnosis on survival benefit of lung transplantation for endstage lung disease. Lancet 351: 24-27.

76. Nichol KL, Margolis KL, Wuorenma J, Von Sternberg T (1994) The efficacy and cost effectiveness of vaccination against influenza among elderly persons living in the community. N Engl J Med 331: 778-784. 
Citation: Khajotia R, Raman K, Khajotia K (2016) Managing Severe COPD: Addressing the Challenges with Latest Trends and Treatment Options (Part II: Non-Pharmacological Management). J Clin Respir Dis Care 2: 121. doi:10.4172/2472-1247.1000121

Page 9 of 9

77. Nichol KL, Nordin J, Mullooly J, Lask R, Fillbrandt K, et al. (2003) Influenza vaccination and reduction in hospitalizations for cardiac disease and stroke among the elderly. N Engl J Med 348: 1322-1332.

78. Tata LJ, West J, Harrison T, Farrington P, Smith C, et al. (2003) Does influenza vaccination increase consultations, corticosteroid prescriptions, or exacerbations in subjects with asthma or chronic obstructive pulmonary disease? Thorax 58: 835-839.

79. Poole PJ, Chacko E, Wood-Baker RWB, Cates CJ (2006) Influenza vaccine for patients with chronic obstructive pulmonary disease. Cochrane Database Syst Rev 1: CD002733.

80. Nichol KL, Baken L, Nelson A (1999) Relation between influenza vaccination and outpatient visits, hospitalization, and mortality in elderly persons with chronic lung disease. Ann Intern Med 130: 397-403.
81. Granger RH, Walters JAE, Poole PJ, Lasserson TJ, Mangtani P, et al. (2006) Injectable vaccines for preventing pneumococcal infection in patients with chronic obstructive pulmonary disease. Cochrane Database Syst Rev 4: CD001390.

82. Nichol KL, Baken L, Wuorenma J, Nelson A (1999) The health and economic benefits associated with pneumococcal vaccination of elderly persons with chronic lung disease. Arch Intern Med 159: 2437-2442.

83. Simonds AK (2006) Care of end stage lung disease. Breathe 4: 315-320.

84. Dales RE, O'Connor A, Hebert P, Sullivan K, McKim D, et al. (1999) Intubation and mechanical ventilation for COPD. Development of an instrument to elicit patient preferences. Chest 116: 792-800.

85. Hahn ME (2006) Advance directives and patient-physician communication. J Am Med Assoc 289: 96. 